SAN DIEGO-The heavy artillery was deployed and the armored defenses set in place as Wall Street analysts and biotech company executives clashed during a panel session of the Biopharmaceuticals Futures Conference held in early October. Sponsored by PaineWebber (New York, $\mathrm{NY}$ ) and Bio/Technology, more than 200 speakers and attendees met here to discuss the impact of the past year's turmoil in the financial markets on biotech companies and their ability to raise new capital. Over three days, the conferees discussed various financing mechanisms-including public-sector financing, venture capital, and strategic partnerships and industry collaborations. Still, it was not these mechanisms, but the public equity market and investor-and analyst-perception of the present and future of biotech that occupied many minds.

PaineWebber analyst Linda Miller, perhaps anticipating the furor to come, discussed in her introductory remarks the impact of the capital markets on the growth of biotechnology companies. Over 75 percent of present funding comes not from the private sector, but from federal and state funding programs, she points out, with the National Institutes of Health dominating. "Washington, not New York, London, or Tokyo, is an important factor for biotechnology business. Focus on the changes taking place there."

In talking about investor attitudes, the analysts on the panel all see investors currently playing earnings growth stories. "But unfortunately," Miller lamented, "biotechnology is not an earnings growth story." Denise Gilbert of Montgomery Securities (San Francisco, CA) sees some light ahead, though. "By the end of 1989 , we see growth in the pharmaceutical stocks and a parallel interest in biotech stocks." Merrill Lynch's (New York, NY) David Manyak agrees, emphasizing that "Interest rates should be lower by the end of 1989, and that should be good for biotech."

When Peter Drake (Vector Securities, Chicago, IL) began to discuss the reasons why analysts have changed their valuation parameters for biotechnology companies over time, some audience frustrations began to

\section{FIRES BACK}

show through: "Biotechnology is in a state of transition, of evolution, and the critical variables for success are going to change as the industry evolves," he began. "In the commercial phase, it is earnings that are driving the stocks."

That emphasis on earnings and valuation methods triggered a sharp challenge from the panel's moderator, Cetus' (Emeryville, CA) president Robert Fildes, and many members of the audience. It appeared to them that, while acknowledging in broad statements the eventual, significant impact of biotech products in the marketplace, the analysts refuse to factor that potential into their projections. As Fildes put it: "You seem to show no vision, no excitement, no understanding of this fantastic industry we're building, and that we've only seen the tip of the iceberg."

That basic conflict, between investors' demands for earnings to support a stock price, and the industry's desire to continue its research efforts, unencumbered by short-term financial pressures, will not disappear.

-Mark Ratner

\section{A Research and Development Company Serving Industry}

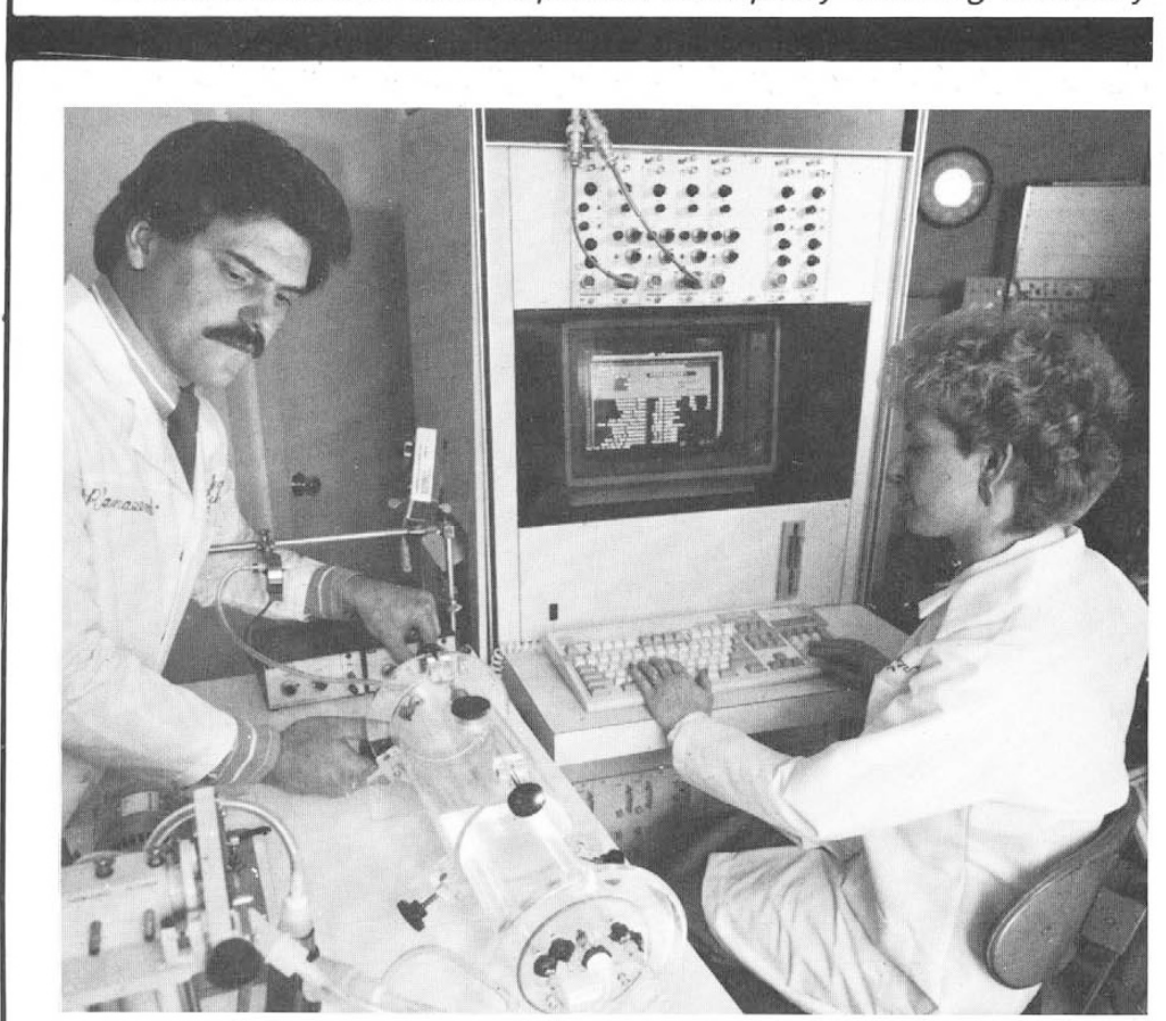

For information regarding the services PHARMAKON offers its clients contact:

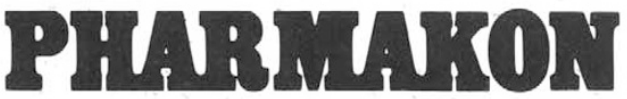

PHARMAKON has twenty-two years of experience in providing quality services to the Pharmaceutical. Chemical and Biotechnology Industries for product development, safety and regulatory compliance. PHARMAKON complies with all aspects of GOOD LABORATORY PRACTICES, and is FDA certified, and AAALAC accredited. PHARMAKON conducts customized testing to meet IND, NDA, and PLA requirements

PHARMACOLOGY/SAFETY

central nervous system (CNS)

cardiovascular system (CV)

gastrointestinal system (GI)

pulmonary system

Does your product

affect these systems?

\section{TOXICOLOGY}

mutagenesis/genetic toxicology

teratology

reproduction/fertility

immunotoxicology

carcinogenesis

QUALITY ASSURANCE

sterility test (21 CFR 610.12)

pyrogen test (21 CFR 610.13)

general safety test

21 CFR 610.11

microbial contamination tests ${ }^{*}$

(MAP test, mycoplasma, bacteria, fungi)

SPECIAL PRODUCT TESTS*

bioassay (in vitro, in vivo)

biodistribution/clearance

dosimetry

tumorigenicity

acute

subacute

chronic

retrovirus tests $X C$ Plaque and $S \cdot / L$ - Focus assay)

Tests under development

Richard J. Matthews, Ph. D.

Pharmakon Research International, Inc.

Waverly, PA 18471 (717) $586-2411$ 